\title{
PEMANFAATAN LAHAN TAK PRODUKTIF SEBAGAI UPAYA EDUKASI SISWA UNTUK MELESTARIKAN LINGKUNGAN
}

\author{
Rasyidah Nur Aisyah ${ }^{1}$, Kuni Arifah ${ }^{2}$, Zakiyah Bahanan ${ }^{3}$, Syakirotun Nimah ${ }^{4}$, Khoirun Nisak S.I. ${ }^{5}$ \\ 1) Pendidikan Bahasa Inggris,' Fakultas Pedagogi dan Psikologi, Universitas PGRI Wiranegara Pasuruan \\ ${ }^{2,3,4,5)}$ Mahasiswa Fakultas Pedagogi dan Psikologi, Universitas PGRI Wiranegara Pasuruan \\ e-mail: ocicyah@gmail.com
}

\begin{abstract}
Abstrak
Akhir-akhir ini sekolah di berbagai daerah pada umumnya hanya sedikit yang memiliki taman sekolah, tetapi semua itu pun tidak dirawat dan dimanfaatkan dengan baik. Upaya menanamkan kesadaran dalam memahami pentingnya mencintai dan melestarikan lingkungan perlu dimulai sejak usia sekolah. Salah satunya melalui program penataan dan pemanfaatan lahan tak produktif sebagai proses pendidikan lingkungan kepada siswa-siswi. Pelaksanaan kegiatan ini bertujuan untuk menciptakan lingkungan sekolah yang kondusif sebagai wujud pola hidup sehat, bersih, asri, dan nyaman untuk proses pembelajaran sekaligus untuk melestarikan alam di Indonesia. Metode yang digunakan diantaranya membuat taman kreasi dengan memanfaatkan barang bekas serta menambah pengadaan tempat sampah sekolah. Pembuatan taman kreasi dilakukan pada sisi samping kelas dan area halaman kantor guru dengan dipenuhi tanaman yang beragam serta meletakkan tempat sampah pada area strategis yang mudah dijangkau oleh siswa-siswi.Hasil dari kegiatan ini kesadaran siswa-siswi sudah mulai tumbuh untuk menjaga dan merawat taman sekolah. Terlihat dari kebiasaan menyiram tanaman yang dilakukan setiap pagi dan setelah pulang sekolah. Siswa-siswi juga membiasakan diri membuang bekas makanan pada tempat sampah pada yang telah disediakan.
\end{abstract}

Kata Kunci: Edukasi, Lingkungan, lahan tak produktif

\begin{abstract}
Lately there are only a few schools in various regions in the world that have a school park, but none of that has been well cared for or utilized. Efforts to instill awareness in understanding the importance of loving and preserving the environment need to begin at school age. One of them is through the program of structuring and utilizing unproductive land as an environmental education process for students. The implementation of this activity aims to create a conducive school environment as a form of a healthy, clean, beautiful, and comfortable lifestyle for the learning process as well as to preserve nature in Indonesia. The methods used include creating a creation park by utilizing used goods and increasing the procurement of school trash bins. The creation of a creative garden is done on the side of the classroom and the office area of the teacher's office filled with diverse plants and places a trash can in a strategic area that is easily accessible to students. The results of this activity students' awareness has begun to grow to maintain and maintain the school garden. Seen from the habit of watering plants that are done every morning and after school. The students also made a habit of throwing food traces in the trash bin that had been provided.
\end{abstract}

Keywords: Education, Environment, Unproductive Land

\section{PENDAHULUAN}

Pembenahan lingkungan fisik sekolah penting dilakukan sebagai upaya meningkatkan kualitas pendidikan. Dengan lingkungan sekolah yang kondusif dan nyaman siswa-siswi akan bergairah untuk belajar. Sehingga proses pembelajaran berjalan efektif dan efisien. 
Sekolah sebagai salah satu lembaga untuk mendidik dan menanamkan budaya positif mempunyai peran yang sangat penting dalam mewujudkan dan menanamkan karakter hidup bersih dan sehat, dan seluruh warga sekolah dapat terlibat secara aktif di dalam menjaga lingkungan hidup. Penataan sekolah dengan konsep sekolah hijau merupakan proses pendidikan lingkungan kepada siswa-siswi yang harus memahami pentingnya mencintai dan melestarikan lingkungan. Salah satunya melalui program penataan dan pemanfaatan lahan tak produktif. Penanaman nilai kebersihan lingkungan terhadap siswa sejak usia dini sangatlah penting, karena siswa merupakan generasi penerus bangsa yang sebaiknya telah dibekali oleh orang dewasa atau guru mengenai halhal yang dapat menjaga lingkungan.

Pembuatan taman kreasi dilakukan sebagai upaya edukasi bagi siswa-siswi dalam merawat lingkungan sekolah. Begitu banyak manfaat dari sebuah taman kreasi, salah satunya sebagai tindakan untuk penghijauan agar sekolah menjadi lebih asri, rindang dan sejuk serta mampu mengurangi sampah, polusi dan kerusakan lingkungan. Tumbuhan yang ada di taman sekaligus sebagai penghasil oksigen, karena kemampuan tumbuhan berfotosintesis dengan menyerap dan mengolah gas karbondioksida $\left(\mathrm{CO}_{2}\right)$ dari udara dan air $\left(\mathrm{H}_{2} \mathrm{O}\right)$ dari dalam tanah dengan bantuan sinar matahari ditambah klorofil maka akan menghasilkan oksigen $\left(\mathrm{O}_{2}\right)$ yang baik yang membuat udara di sekolah menjadi lebih segar.

Kesadaran siswa-siswi untuk tidak membuang sampah sembarangan juga perlu galakkan. Caranya adalah dengan menyediakan tempat pembuangan sampah berupa bak sampah yang terbuat dari limbah kayu yang mana pada area sekolah memang kurang memadai. Sekolah MA Nurul Badri Pasuruan Jawa Timur hanya memiliki satu tempat sampah berukuran sedang yang diletakkan di halaman kantor guru. Hal ini yang menyebabkan halaman sekolah kotor karena kurangnya ketersediaan tempat sampah dibeberapa area yang mudah dijangkau oleh siswa-siswi.

Berawal dari masalah tersebut, kami bekerjasama dengan sekolah berinisiatif melakukan penataan ulang lingkungan sekolah dengan membuat taman kreasi sederhana dan menambah pengadaan tempat sampah sekolah.

\section{METODE}

Edukasi terhadap siswa ini dilaksanakan melalui program pemanfaatan tanah tak produktif yang ada disekitar sekolah, diantaranya depan dan samping kantor madin serta depan kelas XII MA Nurul Badri Pasuruan. Pemanfaatan tanah tak produktif ini diupayakan dengan pembuatan taman kreasi yang dilakukan dengan memanfaatkan barang-barang bekas yang ada disekitar area MA.

Pemanfaatan barang bekas sendiri diawali dengan sosialisasi kepada siswa-siswi MA untuk mengumpulkan barang-barang bekas disekitar area sekolah yang tidak digunakan. Kemudian, dilanjutkan dengan pengajaran mengenai cara memanfatkan barang bekas tersebut hingga dapat menjadikannya bahan untuk membuat taman kreasi serta penambahan tempat sampah di area MA guna meningkatkan kesadaran siswa-siswi untuk membuang sampah pada tempatnya.

\section{HASIL DAN PEMBAHASAN}

Pembuatan taman kreasi dilaksankaan dalam bentuk kegiatan:

\section{Pengumpulan dan Pemanfaatan Barang-Barang Bekas}

Pembuatan taman kreasi dilakukan dengan memanfaatkan barang bekas yang ada disekitar sekolah. Untuk pengumpulan barang bekas ini dilakukan dengan meminta bantuan bantuan pada siswa-siswi MA untuk mengumpulkan barang-barang tak terpakai di area MA untuk nantinya akan diajarkan bagaimana cara menggunakan barang-barang tersebut untuk menjadi bahan taman kreasi. Kemudian, setelah terkumpul, barang-barang tersebut dilanjutkan dengan pemilihan barang mana yang masih layak didaur ulang.

Pemilihan barang-baraang yang masih layak pakai diantaranya pemilihan beberapa botol plastic bekas dengan berbagai ukuran yang akan dimanfaatkan untuk membuat pot. Kemudian untuk taman kreasi sendiri akan direncanakan juga pembuatan pot bunga dari ban bekas. Dikarenakan untuk ban bekas sendiri tidak memungkinkan untuk dikumpulkan oleh siswa-siswi 
MA maka, disiasati dengan membelinya. Selanjutnya untuk hiasan taman sendiri digunakan batubatu sisa pembangunan yang ada disekitar MA untuk dicat ulang setelah mendapat izin dari pihak MA terkait pemanfaatan batu-batu ini.

\section{Pembuatan Pot Bunga dari Botol Plastik}

Pembuatan pot bungan dilakukan dengan memanfaatkan botol-botol plastik yang masih layak digunakan. Proses pengerjaanya sendiri dilakukan dengan menyediakan bahan yang diperlukan diantaranya: botol plastik, cutter atau gunting serta cat. Penggunaan cat ini difungsikan agar pot bunga yang dihasilkan terlihat lebih cantik dan indah.

Proses awal dilakukan dengan membagi botol plastik menjadi dua bagian yang kemudian dilajutkan dengan membuat kreasi dengan kreatifitas sendiri yang dimiliki setiap setiap siswasiswi. Dalam pelaksanaannya terlihat sikap penuh minat dari siswa-siswi MA yang turut membantu dalam pembuatan pola untuk pot bungan ini. Selanjutnya setelah terbentuk model pot bunga yang diinginkan, dilanjutkan dengan pengecatan botol-botol tersebut dengan menggunakan cat yang sudah disediakan.

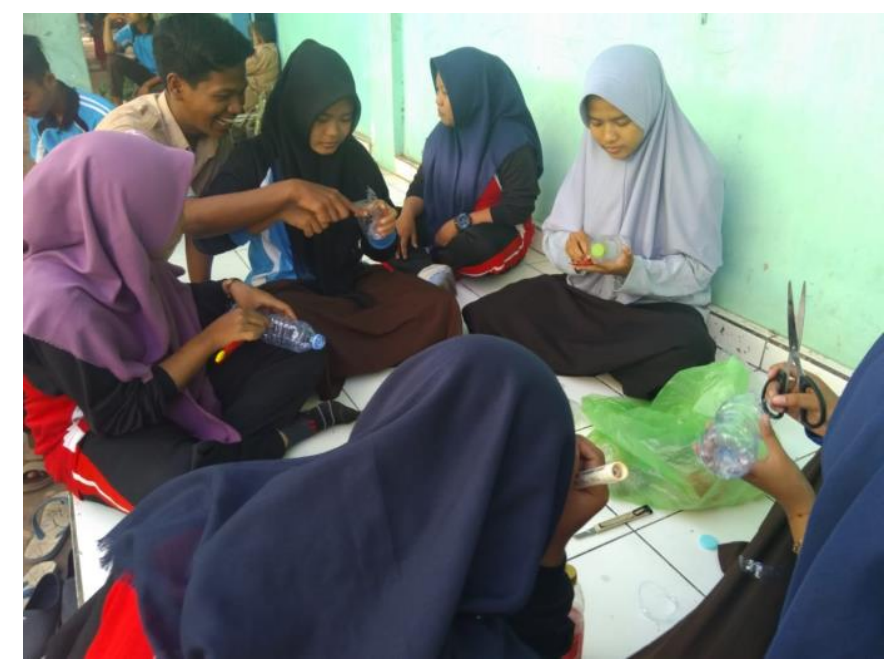

Gambar 1. Pembuatan pot bunga dari botol bekas

\section{Pemilihan dan Penanaman Bunga dalam Pot}

Bunga yang akan ditanam dalam pot yang sudah dibuat serta untuk taman, dipilih berdasarkan sifat bunga yang disesuaikan dengan kondisi tanah serta lingkungan MA. Pemilihan bunga ini dipilih bunga yang mudah perawatannya lantaran kondisi suhu yang saat ini sedikit ekstrim (panas). Bunga yang dipilih diantaranya: lavender, anyelir, vinca, kromosum hijau, kromosum merah, kromosum putih, taiwan, bulu ayam, krokat, brokoli, dan pucuk merah. Selain itu juga dimanfaatkan beberapa bungan yang sudah ada disekitar area MA.

Penanaman bunga dilakukan dengan bantuan siswa-siswi MA guna mengedukasi siswa tentang cara penanaman bunga yang baik. Untuk mensiasasti penggunaan tanah untuk bunga, digunakan sekam padi juga penggunaan tanah organik.

Proses penanaman diawali dengan mencampurkan tanah organik, sekam padi juga pupuk alami untuk media tanam. Setelah media tanam tercampur, media ini dimasukkan pada pot-pot bunga yang sudah jadi lalu ditanami bunga yang sudah ada. Untuk perawatan bunga-bunga hanya dilakukan dengan penyiraman air secukupnya serta bunga-bunga tersebut harus mendapatkan sinar matahari yang cukup. 


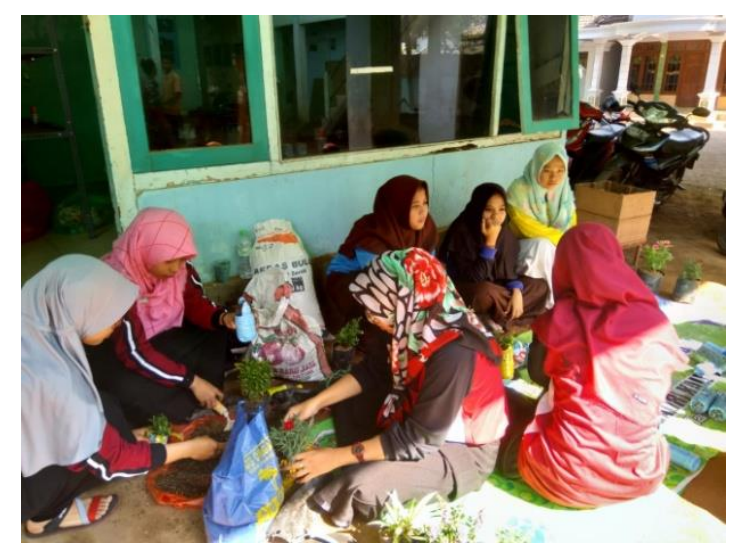

Gambar 2. Proses penanaman bungan

\section{Pembuatan Taman Kreasi}

Proses pembuatan taman kreasi ini diawali dengan pemilihan lokasi yang mana menurut guru pembimbing, tidak semua lokasi di area MA yang dapat dimanfaatkan untuk pembuatan taman lantaran beberapa area tersebut bukan hak milik MA Nurul Badri. Setelah berdiskusi dengan guru pembimbing diperoleh tiga area untuk pembuatan taman kreasi diataranya depan dan samping kantor Madin (Madrasah Diniyah) serta samping kelas XII MA.

Kegiatan pembuatan taman kreasi ini dilakukan dengan pembersihan terlebih dahulu lahan yang akan digunakan untuk pembuatan taman, pembersihan ini dilakukan juga dengan menggemburkan tanah yang akan ditanami. Untuk mempermudah penggemburan tanah ini dilakukan dengan membasahi lahan terlebih dahulu, lantaran kondisi tanah yang lumayan keras dan kering.

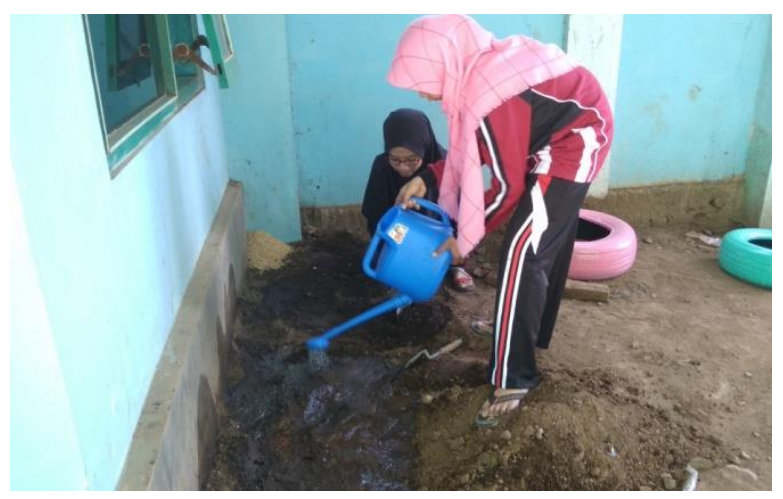

Gambar 3. Proses penggemburan tanah

Kegiatan selanjutnya dilakukan dengan mencampurkan tanah sisa penngemburan tanah, sekam padi dan pupuk organik untuk media tanam. Kemudian tanah campuran digunakan untuk media tanam dalam pot yang memanfaatkan ban bekas yang juga sudah di cat. Setelah media tanam siap selanjutnya dilakukan penanaman bunga. Karena tema yang diusung adalah taman kreasi maka untuk taman pembuatan taman ini juga digunakan batu-batu sisa pembangunan juga terdapat limbah kerang untuk mempercantik taman yang telah ditanami. 


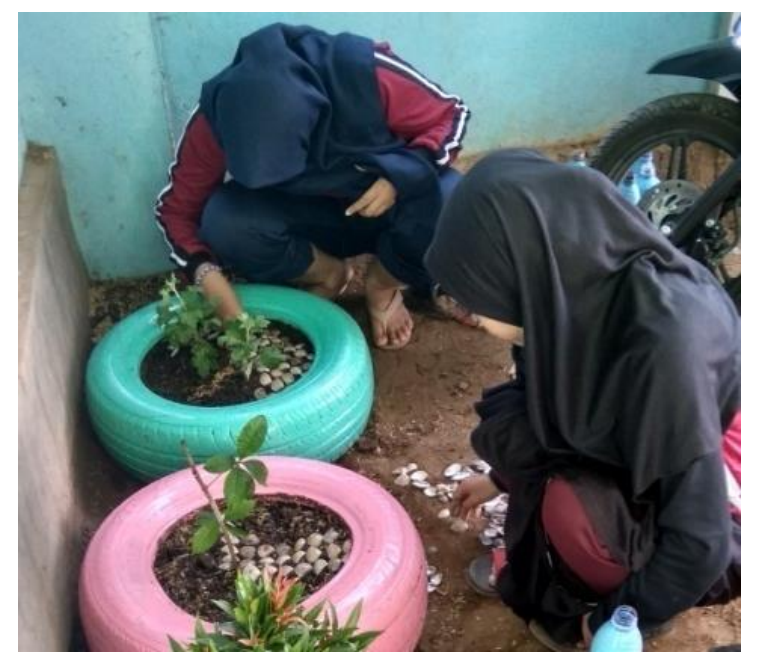

Gambar 4. Proses pemanfaatan limbah kullit kerang

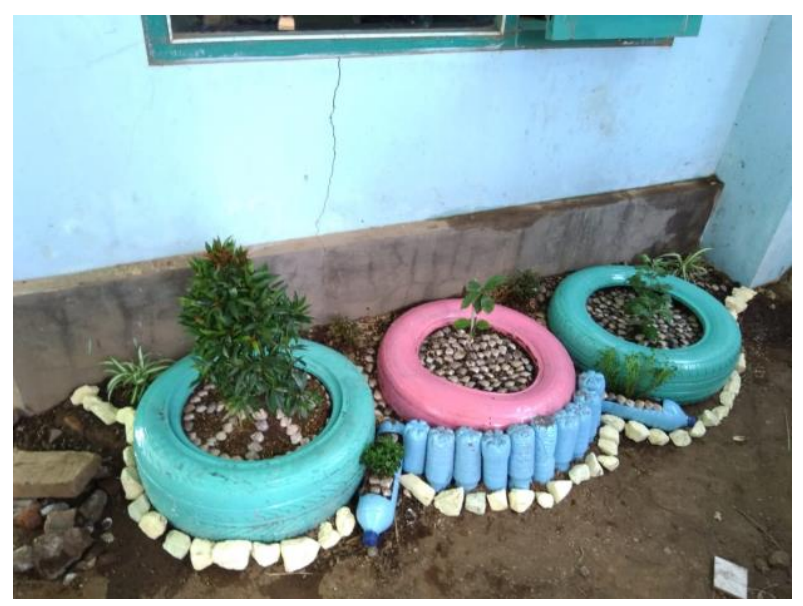

Gambar 5. Hasil Taman Kreasi

\section{Penambahan dan Pengadaan Tempat Sampah}

Penambahan dan pengadaan tempat sampah ini dilakukan dengan membuat tempat sampah dari limbah kayu. Penyediaan tempat sampah warna ini dimaksudkan untuk menumbuhkan kesadaran warga sekolah akan pentingnya menjaga lingkungan sekitar.

Pembuatan tempat sampah diawali dengan pengumpulan limbah kayu di sekitar area MA. Hal ini didasarkan untuk memanfaatkan limbah kayu sisa pembangunan.

Kemudian dari limbah kayu yang sudah terkumpul dibuat tempat sampah dengan ukuran sedang. Pemilihan bahan kayu ini sendiri juga atas saran dari guru pembina yang awalnya akan dibuatkan tempat sampah dari bahan jurigen bekas namun menurut guru pembina jika dibuatkan dari jurigen akan dimanfaatkan oleh siswa menjadi alat pukul perkusi.

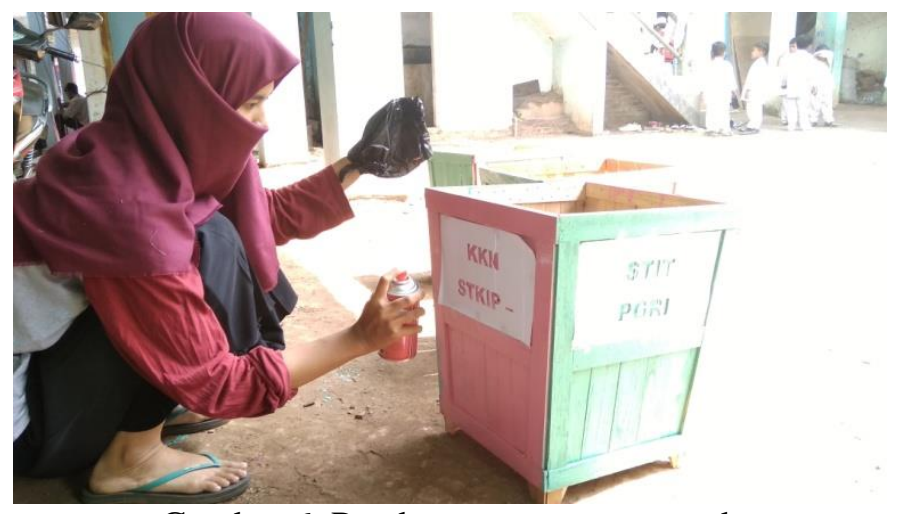

Gambar 6. Pembuatan tempat sampah 


\section{SIMPULAN}

Berdasarkan uraian dalam pembahasan maka dapat disampaikan kesimpulan mengenai hasil KKN di MA Nurul Badri sebagai berikut:

1. Pembuatan taman kreasi mampu membuat lingkungan sekolah yang awalnya gersang dan tandus seta banyak sampah bertebaran menjasi lingkungan sekolah yang asri, indah dan sejuk. Sekaligus mengedukasi siswa-siswi mulai dari menyiapkan dan mengolah lahan taman, menanam bunga, menghias taman serta merawat taman.

2. Pembuatan sampah juga diharapkan agar siswa-siswi tidak lagi membuang sampah sembarangan karena sudah disediakan tempat sampah di masing-masing kelas sehingga tercipta lingkungan sekolah yang bersih dari sampah

\section{DAFTAR PUSTAKA}

Suryani, A.S. 2014. Peranan Bak Sampah Dalam Efektivitas Pengelolaan Sampah (Studi Kasus Bank Sampah Malang). Jakarta: Pusat Pengkajian, Pengolahan Data dan Informasi.

Anam, Khoirul. 2019. Pentingnya Kesadaran akan Pelestarian Lingkungan Sejak Dini, Mahasisiwa KKN UNNES Berikan Sosialisasi Pemilahan Sampah pada Anak-Anak Sekolah Dasar. http://www.googleco.id/amp/s/www.kompasiana.com/amp/khoirulanam1806/5dcbb948097f365 9372cc132/Pentingnya-Kesadaran-akan-Pelestarian-Lingkungan-Sejak-Dini-Mahasisiwa-KKNUNNES-Berikan-Sosialisasi-Pemilahan-Sampah-pada-Anak-Anak-Sekolah-Dasar/.25 Desember 2019.

Karim, Abdul. 2017. Mengembangkan Kesadaran Melestarikan Lingkungan Hidup Berbasis Humanisme Pendidikan Agama. Edukasi: Jurnal Penelitian Pendidikan Islam. 12 (2): 309-329.

Retnowati, Rita \& Istiana, Rita. Membangkitkan Kepedulian Lingkungan mellaui Pemberdayaan Masyarakat guna Menjamin Keberlanjutan Fungsi DAS Citarum. DIFUSI. 2 (2): 1-10. 